\title{
Anomalous kinetics of lath martensite formation in stainless steel
}

\author{
Villa, Matteo; Hansen, Mikkel Fougt; Pantleon, Karen; Somers, Marcel A. J.
}

Published in:

Materials Science and Technology

Link to article, DOI:

10.1179/1743284714Y.0000000709

Publication date:

2015

Document Version

Peer reviewed version

Link back to DTU Orbit

Citation (APA):

Villa, M., Hansen, M. F., Pantleon, K., \& Somers, M. A. J. (2015). Anomalous kinetics of lath martensite formation in stainless steel. Materials Science and Technology, 31(11), 1355-1361.

https://doi.org/10.1179/1743284714Y.0000000709

\section{General rights}

Copyright and moral rights for the publications made accessible in the public portal are retained by the authors and/or other copyright owners and it is a condition of accessing publications that users recognise and abide by the legal requirements associated with these rights.

- Users may download and print one copy of any publication from the public portal for the purpose of private study or research.

- You may not further distribute the material or use it for any profit-making activity or commercial gain

- You may freely distribute the URL identifying the publication in the public portal 


\title{
Anomalous kinetics of lath martensite formation in stainless steel
}

\author{
M. Villa ${ }^{1}$, M. F. Hansen ${ }^{2}$, K. Pantleon ${ }^{1}$ and M. A. J. Somers ${ }^{1}$
}

1. Department of Mechanical Engineering, Technical University of Denmark, DK 2800 Kongens Lyngby, Denmark

2. Department of Micro and Nanotechnology, Technical University of Denmark, DTU Nanotech, DK 2800 Kongens Lyngby, Denmark

\begin{abstract}
The kinetics of lath martensite formation in $\mathrm{Fe}-17.3 \mathrm{wt}-\% \mathrm{Cr}-7.1 \mathrm{wt}-\% \mathrm{Ni}-1.1 \mathrm{wt}-\% \mathrm{Al}-0.08 \mathrm{wt}-\% \mathrm{C}$ stainless steel was investigated with magnetometry and microscopy. Lath martensite forms during cooling, heating and isothermally. For the first time, it is shown by magnetometry during extremely slow isochronal cooling that transformation rate maxima occur, which are interrupted by virtually transformation free temperature regions. Microscopy confirms martensite formation after athermal nucleation of clusters followed by their time dependent growth. The observations are interpreted in terms of time dependent autocatalytic lath martensite formation followed by mechanical stabilisation of austenite during the transformation process.
\end{abstract}

Keywords: Phase transformation kinetics, Martensitic phase transformation, Stainless steel, Magnetometry

\section{INTRODUCTION}

The kinetics of the austenite to martensite transformation in ferrous alloys is classified into two categories: athermal and isothermal. ${ }^{1}$ In the athermal case, the fraction of transformed product does not depend on time and increases instantaneously with increasing driving force for transformation. In the isothermal case, the transformation is time dependent. An alternative interpretation ${ }^{2,3}$ suggests that the athermal reaction is an extremely fast isothermal transformation, making the distinction between the two categories purely hypothetical. The kinetics of martensite formation is classified into isothermal and anisothermal. ${ }^{2}$ Anisothermal transformations apparently proceed ather-mally on cooling (i.e. with increasing the driving force for transformation), but continue isothermally upon inter-rupting the cooling. ${ }^{4,5}$

An additional category of the austenite to martensite transformation kinetics is burst kinetics, ${ }^{6}$ which is characterised by sharp transformation steps on cooling. ${ }^{7}$ In burst kinetics, autocatalytic nucleation of martensite results in the abrupt transformation of a part of the material in an instantaneous and irreproducible transformation event, a so called burst. ${ }^{7}$ A burst takes place within a millisecond ${ }^{8}$ On the other hand, austenite to martensite transformation kinetics characterised by a series of alternating accelerations and decelerations of the trans-formation on cooling is considered an anomaly. ${ }^{3,7,9,10}$ Such anomalous transformation kinetics differs from burst kinetics for the reproducibility ${ }^{9,10}$ and the timescale of the transformation steps, which is in the range $1-10^{4} \mathrm{~s}$.

Martensite in iron based alloys can appear as lath or plate morphology. ${ }^{11}$ The present manuscript focuses on martensite with lath morphology. Lath martensite formation kinetics characterised by a series of alternating retardations and accelerations of the transformation on cooling was demonstrated recently and independently in Refs. 9 and 10. The transformation kinetics was referred to as unusual ${ }^{9}$ and anomalous, ${ }^{10}$ respectively. In 
Ref. 12, where similar observations were reported, the transformation product was bainitic ferrite. ${ }^{13}$ Analogies and differences between the works in Refs. 9 and 10 are listed in the following.

In Ref. 9, a train of transformation rate maxima, i.e. a series of alternating retardations and accelerations of the transformation, was observed with dilatometry and calorimetry on cooling a $\mathrm{Fe}-\mathrm{Ni}-\mathrm{Co}-\mathrm{Mo}$ maraging steel at a rate ranging from $0.2 \mathrm{to} 2.5 \mathrm{Kmin}^{-1}$. Overall, the kinetics of martensite formation on cooling appeared to be controlled by the driving force for transformation (i.e. athermal character), but (partial) isothermal character was identified by a measurable effect of the cooling rate on the transformation steps. As a matter of fact, the transformation rate maxima were more pronounced the faster the cooling, while the temperature at which they were observed, as well as their number, was independent of the cooling rate.

In Ref. 10, a train of transformation rate maxima was observed with dilatometry during cooling of a $\mathrm{Fe}-\mathrm{Cr}-$ $\mathrm{Ni}-\mathrm{Cu}$ martensitic stainless steel at cooling rates ranging from 0.015 to $500 \mathrm{~K} \mathrm{~min}^{-1}$, and anomalous transforma-tion kinetics was observed in the cooling rate range 1.5-50 $\mathrm{K} \mathrm{min}^{-1}$. As for Ref. 9, overall, the kinetics of martensite formation on cooling appeared controlled by the driving force for transformation, but (partial) isothermal character was identified by a measurable effect of the cooling rate on the transformation steps. Moreover, isothermal martensite formation was demonstrated on interrupting the cooling. These observations are consistent with anisothermal transformation kinetics. The number of transformation rate maxima depended on the cooling rate and was $12,9,6$ and 5 for cooling rates of $1.5,5,15$ and $50 \mathrm{~K} \mathrm{~min}^{-1}$ respectively. For a cooling rate up to $15 \mathrm{~K} \mathrm{~min}^{-1}$, the transformation rate maxima also became more pronounced the faster the cooling. Despite strong similarities in the observed transformation kinetics, the mechanisms proposed to explain the observed trains of transformation rate maxima were different for the systems investigated in Refs. 9 and 10.

In Ref. 9, the train of transformation rate maxima was interpreted as the result of the simultaneous formation of specifically oriented martensite blocks within packages, throughout the specimen. The formation of lath marten-site subdivides the austenite grains at different length scales. ${ }^{14-16}$ First, austenite grains are divided into packets. Each packet contains several parallel blocks of martensite laths. The individual laths represent the smallest level of subdivision. Hence, according to Ref. 9, during the evolution of the transformation, the units of martensite are distributed over the majority of the (prior) austenite grains. This hypothesis was verified in the surface region of the material by in situ optical microscopy. ${ }^{17}$

Conversely, in Ref. 10, the train of transformation rate maxima was interpreted as the result of the interplay between the driving force for thermally activated autocatalytic martensite formation and the counteracting mechanical stabilisation of the austenite (see below) during the transformation. Moreover, according to Ref. 10 , the units of martensite are not distributed over the majority of (prior) austenite grains but are grouped in clusters, which nucleate independently, while their growth is thermally activated and extends over several (prior) austenite grains. This interpretation is based on previous work on the formation of lath martensite in a $\mathrm{Fe}-\mathrm{Cr}-\mathrm{Ni}-\mathrm{Al}$ stainless steel ${ }^{18}$ where clusters of martensite units were observed at the surface of the material together with numerous unaffected austenite grains. Moreover, two transformation rate maxima were revealed by magnetometry upon isochronal cooling of the material at $0.1 \mathrm{~K} \mathrm{~min}^{-1} .^{18}$

The interpretation of the transformation mechanism reported in Ref. 10 takes into account the effects of the transformation induced elastic (i.e. stress) and plastic strains introduced in martensite and surrounding austenite. ${ }^{19-22}$ Elastic and plastic strains are responsible for both the autocatalytic character of the transformation and the mechanical stabilisation of the austenite. 8 Hydrostatic (elastic) stress reduces the driving force for the austenite to martensite transformation ${ }^{23-25}$ and consequently counteracts the continuation of martensite development ${ }^{26}$ (i.e. mechanically stabilises the austenite ${ }^{27}$ ). Conversely, shear stress thermodynamically promotes both (stress assisted) ${ }^{28}$ nucleation and growth ${ }^{29}$ of martensite and may yield autocatalytic behaviour. ${ }^{11,27,30}$ Plastic deformation by the introduction of dislocations in austenite counteracts the movement of an existing martensite/austenite interface into austenite (i.e. mechanically stabilises the 
austenite $\left.^{31}\right) \cdot{ }^{22,31-33}$ On the other hand, dislocations in austenite have been considered as martensite nucleation site $^{28,34}$ and consequently can promote martensite formation and autocatalysis.

Finally, according to Refs. 35 and 36, the kinetics of athermal/anisothermal transformations is governed by the overall balance between driving force for transforma-tion and counteracting mechanical stabilisation of the austenite. Consequently, the interpretation of anomalous transformation kinetics in Ref. 10 is consistent with the interpretation of athermal/anisothermal transformation kinetics in Refs. 35 and 36.

The purpose of the present manuscript is to contribute to the experimental validation of the description of anomalous martensite formation kinetics presented in Ref. 10, and thereby to the understanding of the mechanism(s) underlying the kinetics of lath martensite formation in stainless steels.

\section{MATERIALS AND METHODS}

The material used in this present work was $0.15 \mathrm{~mm}$ thick foil of $\mathrm{Fe}-17.3 \mathrm{wt}-\% \mathrm{Cr}-7.1 \mathrm{wt}-\% \mathrm{Ni}-1.1 \mathrm{wt}-\% \mathrm{Al}-$ $0.08 \mathrm{wt}-\% \mathrm{C}$ stainless steel (commercial grade AISI 631 supplied by Goodfellow Cambridge Ltd) in as rolled condition. In this alloy, the martensitic transformation proceeds from face centred cubic $\mathrm{c}$ to body centred tetragonal a', and martensite has lath morphology. ${ }^{18,37}$ Martensite formation occurs isothermally at temperatures lower than $\sim 310 \mathrm{~K},{ }^{18}$ and isothermal martensite formation is industrially exploited at subzero Celsius temperature. ${ }^{38,39}$ Austenite is metastable at room temperature and transforms into a9 martensite upon mechanical deformation, ${ }^{38,39}$ ion implantation ${ }^{40,41}$ and electropolishing.

Samples were discs, $3 \mathrm{~mm}$ in diameter, which were austenitised in argon at $1127 \pm 10 \mathrm{~K}$ for $4.5 \mathrm{ks}$, cooled in an argon flow at an approximate average rate of $20 \mathrm{~K} \mathrm{~min}^{-1}$ and stored at room temperature for $\sim 2.5 \mathrm{Ms}$ ( 1 month) before investigation. After austenitisation and room temperature storage, the samples are dual phase, composed of austenite and martensite. ${ }^{18,38,39}$

Martensite formation was investigated by vibrating sample magnetometry (VSM) reflected light microscopy (RLM) and scanning electron microscopy (SEM). Microscopy was performed on the surface of the material as prepared before austenitisation. Consequently, the formed martensite is conceived as surface martensite, ${ }^{42}$ which is not necessarily representative of the transformation product in the bulk of the material. ${ }^{43}$ It is hereby assumed that the distribution of the martensite units within the prior austenite grains situated on the sample surface is representative for the distribution of the martensite units in the bulk of the material.

Vibrating sample magnetometry was performed with a Lake Shore Cryotronics 7407 vibrating sample magnetometer, equipped with a Janis SuperTran VP continuous flow cryostat. The degree of transformation was followed by recording the magnetic moment of the sample under an applied magnetic field of $0.3 \mathrm{~T}$, which was sufficient to approach magnetic saturation in the samples. At magnetic saturation, the magnetisation of paramagnetic phases (i.e. c austenite ${ }^{44}$ and e martensite, ${ }^{45}$ when present) is several orders of magnitude smaller than the magnetisation of ferromagnetic phases (i.e. a' martensite). ${ }^{46-48}$ Moreover, the magnetisation at saturation of a phase is not sensitive to structural features such as crystallographic defects. $^{46-48}$

The molar fraction of lath martensite $f_{a^{\prime}}$ in the material is determined on the basis of the following assumptions (see Ref. 18):

(i) the structure of the as rolled material is fully a' martensite ${ }^{37}$ and remains stable in the temperature interval under investigation;

(ii) the molar fraction of a' martensite is proportional to the magnetic moment of the material under an applied magnetic field of $0.3 \mathrm{~T}$, corrected for its dependence on temperature;

With these assumptions, $\mathrm{f}_{\mathrm{a}^{\prime}}(\mathrm{t}, \mathrm{T})$ is given by: 
where $\mathrm{M}(\mathrm{t}, \mathrm{T})$ is the magnetic moment of the sample, and $\mathrm{M}_{\mathrm{a}^{\prime}}(\mathrm{t}, \mathrm{T})$ is the magnetic moment measured in the as rolled material during recording of the baseline under applied magnetic field of $0.3 \mathrm{~T}$.

Samples were subjected to six different thermal cycles, which are labelled A, B and C and 1, 2 and 3 to indicate two different sets of experiments. Samples are labelled A, B, C, 1, 2 and 3, accordingly. In the first set of experiments, samples were subjected to the following thermal cycles:

(i) sample A was isochronally cooled to $80 \mathrm{~K}$ at $10 \mathrm{~K} \min 21$ and thereafter (re)heated to room temperature at $10 \mathrm{~K} \mathrm{~min}^{-1}$;

(ii) sample B was immersed in boiling nitrogen, there after installed in the cryostat, that was precooled to $80 \mathrm{~K}$, and finally isochronally (re)heated to room temperature by applying different heating rates ranging from 0.1 to $10 \mathrm{~K} \mathrm{~min}^{-1}$;

(iii) sample $\mathrm{C}$ was first immersed in boiling nitrogen, then upquenched to room temperature by immersion in water and immediately hereafter installed in the VSM/RLM to follow isothermal martensite formation at room temperature in the first $7.2 \mathrm{ks}$.

In order to relate the results obtained for cycles A, B and C to the works presented in Refs. 9 and 10, a second set of experiments was performed:

(i) sample 1 was mounted in the cryostat precooled to $290 \mathrm{~K}$ and thereafter cooled to $260 \mathrm{~K}$ at $0.015 \mathrm{~K} \mathrm{~min}^{-1}$;

(ii) sample 2 was immersed in boiling nitrogen, upquenched to room temperature by immersion in water, stored for $7.2 \mathrm{ks}$ at room temperature (identical to treatment C) and finally cooled to 260 $\mathrm{K}$ at $0.015 \mathrm{~K} \mathrm{~min}^{-1}$ (identical to treatment 1 );

(iii) sample 3 was mounted in the cryostat precooled to $290 \mathrm{~K}$ (identical to treatment 1 ) and thereafter cooled to $260 \mathrm{~K}$ at $0.05 \mathrm{~K} \mathrm{~min}^{-1}$.

\section{RESULTS AND DISCUSSION}

\section{Martensite formation during cooling, heating and isothermal holding}

In the first series of experiments, the material in the initial condition is (partially) transformed to martensite (Fig. 1). The fraction of $a^{\prime}$ martensite $f_{a^{\prime}}$ in the initial condition is $7 \%$ as quantified with VSM.

In sample A, martensite forms both during isochronal cooling $10 \mathrm{~K} \mathrm{~min}^{-1}$ and subsequent isochronal heating at the same rate. The majority of the transformation is observed during cooling in the temperature interval $220-260 \mathrm{~K}$. Continued transformation appears hindered at temperatures below $\sim 170 \mathrm{~K}$ and is negligible upon reheating for temperatures higher that $\sim 260 \mathrm{~K}$. On cooling, a single transformation rate maximum located at ,245 $\mathrm{K}$ is observed. The fraction of a9 martensite at the end of the thermal cycle is $82 \%$.

In sample B, measurable martensite formation is suppressed during quenching in boiling nitrogen. Instead, martensite develops during the subsequent isochronal heating to room temperature. Martensite formation on heating is irreconcilable with athermal transformation kinetics. Moreover, a heating rate dependent transformation curve implies that the development of martensite is thermally activated. A kinetic analysis of the data at 33\%, 50\% and 67\% transformation (cf. Ref. 49) yielded activation energies of 9, 13 and $17 \mathrm{~kJ}$ $\mathrm{mol}^{-1}$ respectively. These values, which progressively increase with the degree of transformation, are consistent with literature data for isothermal martensite formation in $\mathrm{Fe}-\mathrm{Ni}-\mathrm{Cr}$ alloys and suggest that the movement of dislocations in austenite could be the rate limiting step for thermally activated martensite formation. ${ }^{18,50,51}$ In particular, an increase in the activation energy for martensite formation during the transformation was reported in Ref. 50 and interpreted in terms of progressive hardening of the austenite 
phase as caused by martensite formation. The fraction of martensite at the end of the thermal cycle depends on the heating rate and decreases from 88 to $80 \%$ for increasing the heating rate from 0.1 to $10 \mathrm{Kmin}^{-1}$. Evidently, martensite for-mation can be (partially) suppressed on heating.

Sample $\mathrm{C}$ shows that measurable martensite formation after quenching in boiling nitrogen can be suppressed during subsequent upquenching to room temperature in water. Instead, martensite forms isothermally at room temperature. Considering the extended storage time of 1 month at room temperature before thermal cycle $\mathrm{C}$, this result cannot be interpreted in terms of spontaneous thermally activated nucleation of martensite at room temperature. Martensite formation in Fig. 1c can only be interpreted consistently if growth of martensite does not occur instantaneously upon its nucleation (i.e. growth is, at least partially, thermally activated). Clearly, quenching in boiling nitrogen induces nucleation of martensite, but its growth is to a certain extent hindered at this temperature. The activation energy for thermally activated martensite formation is interpreted in terms of the activation energy for moving the martensite/austenite interface (i.e. the movement of interfacial dislocations) into (strengthened) austenite.18 The transformation at room temperature ceases after, $1.5 \mathrm{ks}$ at a transformed fraction of $30 \%$.

The RLM and SEM images at various stages of cycle C (on a separate sample) are shown in Fig. 2a-c and Fig. $2 \mathrm{~d}$ respectively. Clearly, the martensite units are grouped in clusters, which extend over neighbouring (prior) austenite grains (Fig. 2d).
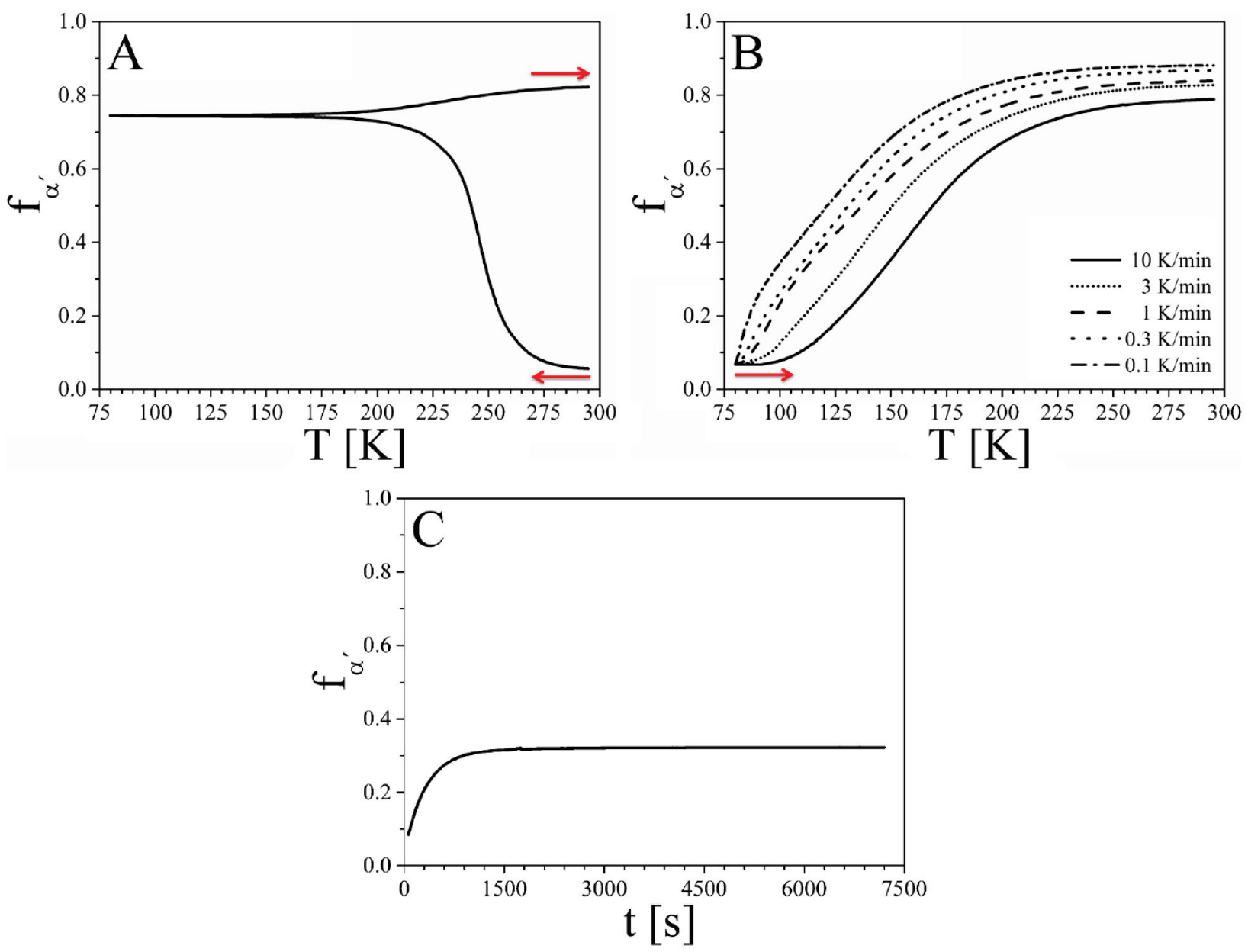

Figure 1. Fractionofmartensitefa9 measured using VSM and plotted versus temperature Tor time t for thermal cycles $A, B$ and $C$, respectively. 


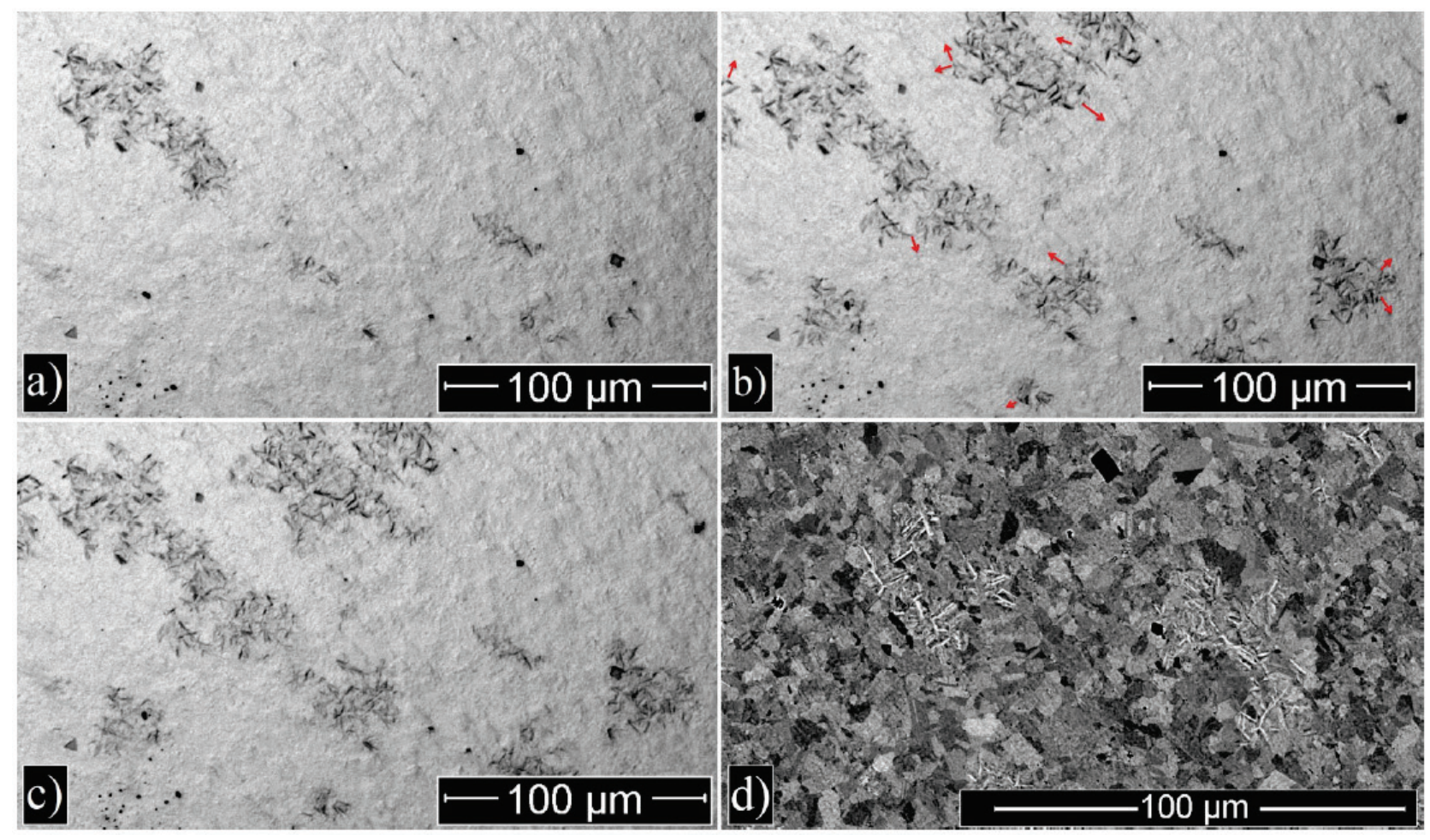

Figure 2. $a-c)$ RLM of sample surface during cycle $C$ : a) initial condition; b) after immersion in boiling nitrogen and in water; c) after $7.2 \mathrm{ks}$ isothermal holding at room temperature; d) SEM-backscatter electron image of sample surface after thermal cycle C. Arrows in b indicate regions on sample surface where isothermal martensite formation occurs.
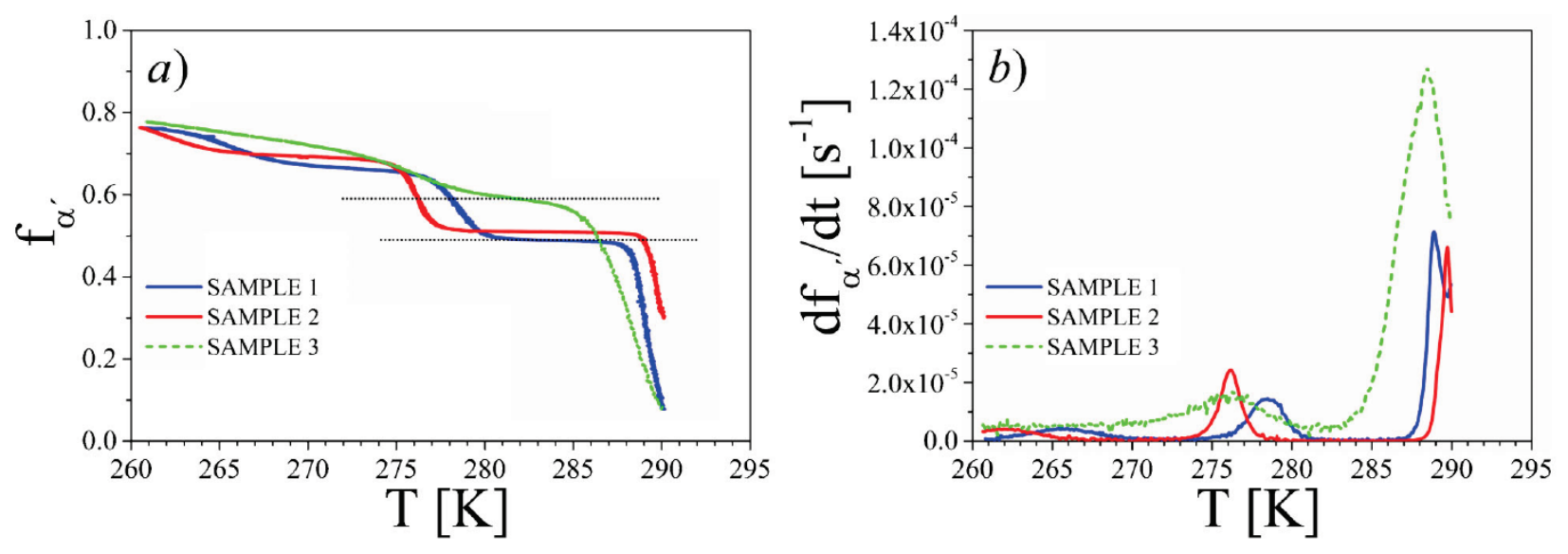

Figure . a) fraction of martensite $f a^{\prime}$ and b) transformation rate fa' $/ d t$ versus temperature T measured using VSM during very slow controlled cooling at 0 ? $015 \mathrm{~K}$ min 21 for samples 1 and 2 and $0 ? 05 \mathrm{~K}$ min- 1 for sample 3. For samples 1 and 2, transformation curves extend over 32.5 h for cooling $30 \mathrm{~K}$; for sample 3, same temperature region is covered in $10 \mathrm{~h}$.

After austenitisation and storage, only few clusters exist (Fig. 2a). Immersion in boiling nitrogen followed by immersion in water generates new clusters (Fig. 2b). Detailed investigation of the mechanism that promotes the athermal nucleation of independent martensite clusters on quenching/upquenching is beyond the scope of the present work. It is anticipated that thermal strains may play a role. Thermal strains are classified in macrostrains and microstrains (see Ref. 52). Macrostrains of thermal origin are a consequence of thermal gradients in the sample, which cannot be excluded for the quenching/upquenching steps. Microstrains of 
thermal origin are expected upon (also slow) cooling/heating of the material as a consequence of the elastic and plastic interaction among phases (i.e. austenite and martensite possess different elastic and thermal properties) as well as among differently oriented austenite grains (i.e. the elastic and plastic properties of the face centred cubic crystal depend on the crystallographic direction53). The mechanical interaction among neighbouring austenite grains may be responsible for the spontaneous athermal nucleation of independent martensite clusters.

During isothermal holding at room temperature, the martensite clusters that form in the quenching and upquenching steps grow (cf. Fig. $2 \mathrm{~b}$ and c), while the initially present clusters remain unaffected. Note that only minor differences are observed between Fig. $2 \mathrm{~b}$ and Fig. 2c. This is caused by the delay due to sample movement from the water bath to the microscope. As shown in Fig. 1 for treatment $\mathrm{C}$, most martensite forms in the initial stage of isothermal holding. Evidently, during time dependent martensite formation, the transformation spreads gradually throughout the material until a saturation point is reached for a certain transformed fraction. Furthermore, thermal energy alone cannot promote martensite formation until completion, as a certain level of undercooling, i.e. an additional driving force, is required for continued transformation (consider Fig. 1b and com-pare Fig. 1c with Fig. 1a and b).

\section{Anomalous kinetics of martensite formation}

Martensite formation during the second series of experiments is described in Fig. 3. In Fig. 3a and b, the molar fraction of martensite $\mathrm{f}_{\mathrm{a}^{\prime}}$ and the transformation rate $\mathrm{df}_{\mathrm{a}^{\prime}} / \mathrm{dt}$ as measured by VSM during extremely slow cooling at $0.015 \mathrm{~K} \mathrm{~min}^{-1}$ (samples 1 and 2) and at $0.05 \mathrm{~K} \mathrm{~min}^{-1}$ (sample 3) are shown as a function of temperature T. Data for samples 1 and 2 are discussed first, and the mechanism for anomalous transformation kinetics is addressed. Thereafter, the effect of the cooling rate on the transformation kinetics is discussed by comparison of data for samples 1 and 3 .

Clearly, martensite formation during extremely slow isochronal cooling takes place in steps. For both thermal cycles 1 and 2, three distinct transformation steps are observed (Fig. 3a). The extremely slow controlled cool-ing of $0.015 \mathrm{~K} \mathrm{~min}^{-1}$ (i.e. $0.9 \mathrm{~K} \mathrm{~h}^{-1}$ ) excludes thermal gradients in the samples during transformation and demonstrates that the observed effect is a genuine feature of the kinetics of the transformation, rather than an experimental artefact. The maxima of the transformation rate are observed at $\sim 289 \mathrm{~K}, 278 \mathrm{~K}$ and $266 \mathrm{~K}$ for sample 1and at $\sim 290 \mathrm{~K}, 276 \mathrm{~K}$ and $262 \mathrm{~K}$ for sample 2 (Fig. 3b). Exact reproducibility of these temperature values was not investigated. In the light of the microscopy results (i.e. Fig. 2), the data are interpreted as follows.

Below the martensite start temperature, lath martensite nucleates athermally and spontaneously at the most favourable locations in the sample. ${ }^{54}$ Additional sponta-neous nucleation events take place athermally at less favourable locations during cooling. These spontaneous nucleation events are more numerous for a larger driving force experienced by the sample during the thermal cycle, ${ }^{55,56}$ i.e. more numerous in sample 2 as compared to sample 1. Hence, as compared to sample 1, more nuclei have developed spontaneously (and at different locations) in sample 2 during quenching in boiling nitrogen, while their growth was hindered by subsequent upquenching in water.

After athermal nucleation, martensite nuclei grow. Growth is, at least partly, thermally activated ${ }^{18}$ and induces autocatalytic nucleation of martensite blocks/packets in the austenite surrounding the martensite cluster. Consequently, the onset of autocatalytic nucleation is time dependent (cf. Fig. $2 \mathrm{~b}$ and c). Moreover, the growth of autocatalytically formed nuclei is (at least partially) time dependent.

Since spontaneous martensite nucleation occurred at a larger number of locations in sample 2 than in sample 1 (see above), more numerous martensite clusters are present in sample 2 (the same reasoning applies to Fig. $2 \mathrm{a}$ and $\mathrm{b} / \mathrm{c}$ ). As follows from Figs. 1c and 2d, these clusters extend over several neighbouring (prior) 
austenite grains and have reached a stable dimension in both samples 1 and 2 before investigation (note that sample 2 was treated analogously to sample $\mathrm{C}$ before extremely slow isothermal cooling). This result is interpreted in terms of mechanical stabilisation of the austenite during martensite formation. Mechanical stabilisation of the austenite results from strengthening of the austenite phase, which inhibits the movement of the martensite/austenite interface. ${ }^{31}$ Hence, stabilisation of the austenite occurs in the surroundings of each martensite cluster and inhibits its continued growth.

In order for the martensite clusters to spread, further growth of martensite and growth induced autocatalytic nucleation of a new population(s) of martensite blocks/packets are required. This is only possible when additional undercooling augments the driving force for martensite formation and results in an acceleration of the transformation, as corroborated by the first transformation rate maximum observed on cooling $\sim 290 \mathrm{~K}$. Moreover, this description is in agreement with Fig. 2, where only the clusters formed during quenching in boiling nitrogen and subsequent upquenching to room temperature in water were observed to grow during isothermal holding at room temperature (cf. Fig. 2a-c). No growth of the initially present clusters during isothermal holding at room temperature can occur, because they have stabilised before investigation.

During continuous cooling of samples 1 and 2, martensite formation strengthens the adjacent austenite, thereby suppressing further growth. ${ }^{31}$ Consequently, autocatalytic nucleation is retarded. A new acceleration of the transformation occurs when additional undercooling augments the driving force for martensite transformation, promoting growth of martensite and the nucleation of new populations of martensite blocks/packets. Upon further cooling, this mechanism is repeated simultaneously at several locations in the sample, leading to the observation of the second and third (and subsequent...) transformation rate maxima.

In the following, data for samples 1 and 3 are compared and the effect of the cooling rate on the transformation kinetics is discussed in the light of the interpretation of the anomalous kinetics of martensite formation in Ref. 10.

During cooling of sample 3, two transformation steps are observed (Fig. 3a). The transformation rate maxima are reported at $\sim 288 \mathrm{~K}$ and $276 \mathrm{~K}$ (Fig. 3b). Evidently, the number of transformation rate maxima in the temperature interval of investigation depends on the cooling rate and is reduced from three to two by increasing the cooling rate from $0.015 \mathrm{~K} \mathrm{~min}^{-1}$ (i.e. samples 1 and 2) to $0.05 \mathrm{~K} \mathrm{~min}^{-1}$ (i.e. sample 3). Moreover, the first transformation step is completed at $\sim 283 \mathrm{~K}$, corresponding to a transformed fraction of , $58 \%$ (higher horizontal dotted line in Fig. 3a), whileinsample1, it was completed at $\sim 286 \mathrm{~K}$, corresponding to a transformed fraction of $48 \%$ (lower horizontal dotted line in Fig. 3a).

According to Ref. 10, the austenite to martensite transformation stops when the overall strain energy introduced into the system by martensite formation, hereby reinterpreted in terms of mechanical stabilisation of austenite, equals the driving force for transformation. As a consequence of (partial) isothermal character of the transformation, this condition is firstly satisfied at a lower temperature, i.e. at a larger value of driving force, the faster the cooling. In the present work, this condition is satisfied at $286 \mathrm{~K}$ and $283 \mathrm{~K}$ in sample 1 and sample 3 respectively. It follows that a larger degree of transformation is obtained in sample 3 as compared to sample 1 prior that the transformation comes to a halt at the end of the first transformation step. Similar consideration applies to the second, third (and subsequent...) transformation steps.

In Ref. 10, a shift to lower temperature for the first transformation step at faster cooling was suggested, but remained unresolved (i.e. the interpretation remained speculative). Furthermore, the transformation was not suppressed upon cooling at a rate as high as $500 \mathrm{~K} \mathrm{~min}^{-1}$. Overall, the kinetics of martensite formation was ani-sothermal. In the present case, the isothermal character of the transformation is more pronounced, most likely because of the temperature interval of investigation (see Ref. 51), which is 260-290 K versus 333-413 $\mathrm{K}$ in Ref. 10. Consequently, the transformation is suppressed by fast cooling, and the mechanism of anomalous transformation kinetics is revealed. 
In summary, by comparing the transformation curve on cooling samples 1 and 3 , it is evident that martensite formation is macroscopically anisothermal, provided that a sufficiently low cooling rate (i.e. $\leq 0.05 \mathrm{~K} \mathrm{~min}^{-1}$ ) is applied. At a low cooling rate, partial isothermal character is observed by a measurable effect of the cooling rate on the transformation kinetics and a series of controlled transformation steps are observable. The number of transformation steps is a function of the cooling rate. The kinetics of lath martensite formation characterised by multiple controlled transformation steps on slow cooling is labelled anomalous after Ref. 10 .

Macroscopically, anisothermal kinetics is interpreted in terms of an overall balance of driving force and counter-acting mechanical stabilisation of the austenite, in agreement with the description of the kinetics of martensite formation in Refs. 35 and 36. However, as shown by the higher transformed fraction at the start of controlled cooling for sample 2 as compared to sample 1 (Fig. 3a), this description does not apply for the initial stage of the transformation. Here, the overall fraction transformed depends on the number of martensite clusters present in the material. This may be explained by an overall interaction among the different martensite clusters (and their corresponding surrounding strengthened austenite), which takes place only for a sufficiently large fraction transformed.

\section{CONCLUSIONS}

A series of accelerations and retardations of the transformation during very slow isochronal cooling was reported for martensite formation in $\mathrm{Fe}-17.3 \mathrm{wt}-\% \mathrm{Cr}-7.1 \mathrm{wt}-\% \mathrm{Ni}-1.1 \mathrm{wt}-\% \mathrm{Al}-0.08 \mathrm{wt}-\% \mathrm{C}$ stainless steel. This anomalous martensite formation kinetics is interpreted in terms of the combined effect of time dependent martensite formation and mechanical stabilisation of the austenite phase during the transformation process. In situ microscopy supports the interpretation and shows that martensite formation occurs by athermal spontaneous nucleation of martensite in clusters followed by time dependent growth of the clusters by autocatalytic nucleation of martensite over neighbouring prior austenite grains.

\section{REFERENCES}

1. N. N. Thadhani and M. A. Meyers: 'Kinetics of isothermal martensitic transformation', Prog. Mater. Sci., 1986, 30, 1-37.

2. V. Raghavan and M. Cohen: 'Measurement and interpretation of isothermal martensitic kinetics', Met. Trans., 1971, 2, (9), 2409-2418.

3. A. R. Entwisle: 'Kinetics of martensite formation in steel', Met. Trans., 1971, 2, 2395-2407.

4. S. C. DasGupta and B. S. Lement: 'Isothermal formation of martensite at subzero temperatures in high chromium steel', Trans. AIME J. Met., 1951, 191, 727-731.

5. M. Lin, G. B. Olson and M. Cohen: 'Distributed-activation kinetics of heterogeneous martensitic nucleation', 1992, 23A, (11), 2987-2998.

6. A. R. Entwisle and V. Raghavan: 'Isothermal martensite kinetics in iron alloys', J. Iron Steel Inst., 1965, 30-37.

7. R. Brook and A. R. Entwisle: 'Kinetics of burst transformation to martensite', J. Iron Steel Inst., 1965, 203, (9), 905-912.

8. V. Raghavan: 'Kinetics of martensitic transformations', in 'Martensite', (ed. G. B. Olson and W. S. Owen), 1992, 202-225; Metals Park, OH, ASM.

9. S. Lo“ wy, B. Rheingans, S. R. Meka and E. J. Mittemeijer: 'Unusual martensite-formation kinetics in steels: observation of discontin- uous transformation rates', Acta Mater., 2014, 64, 93-99.

10. M. Villa, K. Pantleon, M. Reich, O. Kessler and M. A. J. Somers: 'Kinetics of anomalous multistep martensite formation in steel', Acta Mater., 2014, 80, 468-477. 
11. G. McDougall and C. M. Wayman: 'Crystallography and morphol- ogy of ferrous martensite' in 'Martensite', (ed. G. B. Olson and W. S. Owen), 1992, 202-225; Metals Park, OH, ASM.

12. K. Tsuzaki, T. Maki and I. Tamura: 'Isothermal character and cooling rate dependence of lath martensitic transformation in Fe- 15\%Ni alloy', Scr. Metall., 1987, 21, 1693-1698.

13. E. A. Wilson, S. P. Allen and J. Butler: 'cRa-transformation in Fe-15Ni', Met. Sci., 1982, 16, 539.

14. S. Morito, X. Huang, T. Furuhara, T. Maki and N. Hansen: 'The morphology and crystallography of lath martensite in steel', Acta Mater., 2006, 54, 5323-5331.

15. H. Kitahara, R. Ueji, N. Tsuji and Y. Minamino: 'Crystallographic features of lath martensite in low-carbon steel', Acta Mater., 2006, 54, (5), 1279-1288.

16. S. Morito, H. Tanaka, R. Konishi, T. Furuhara and T. Maki: 'The morphology and crystallography of lath martensite in Fe-C alloys', Acta Mater., 2003, 51, (6), 1789-1799.

17. S. Lo“ wy, B. Rheingans, S. R. Meka and E. J. Mittemeijer: unpublished results.

18. M. Villa, M. F. Hansen, K. Pantleon and M. A. J. Somers: 'Thermally activated growth of lath martensite in $\mathrm{Fe}-\mathrm{Cr}-\mathrm{Ni}-\mathrm{Al}$ precipitation hardenable stainless steel', Mater. Sci. Technol., 2015, 31, (1), 115-122.

19. M. Villa, K. Pantleon and M. A. J. Somers: 'Martensitic transforma- tion and stress partitioning in a high-carbon steel', Scr. Mater., 2012, 67, (6), 621-624.

20. K. Ja. Golovchiner: 'Changes in the lattice parameter of austenite during martensitic transformation of steel', Phys. Met. Metallogr., 1974, 37, (2), 126.

21. G. Miyamoto, A. Shibata, T. Maki and T. Furuhara: 'Precise measurement of strain accommodation in austenite matrix surrounding martensite in ferrous alloys by electron backscatter diffraction analysis', Acta Mater., 2009, 57, (4), 1120-1131.

22. B. Edmondson and T. Ko: 'Spontaneous deformation of austenite during martensitic transformations', Acta Metall., 1954, 2, 235-241.

23. J. R. Pati and M. Cohen: 'Criterion for the action of applied stress in the martensitic transformation', Acta Mater., 1953, 1, (5), 531-538.

24. T. Kakeshita, T. Saburi and K. Shimizu: 'Effects of hydrostatic pressure and magnetic field on martensitic transformations', Mater. Sci. Eng. A, 1999, A273-A275, 21-39.

25. Z. L. Xie, B. Sundqvist, H. Hanninen and J. Pietikainen: 'Isothermal martensitic transformation under hydrostatic pressure in an Fe-Ni-C alloy at low temperature', Acta Metall. Mater., 1993, 41, (8), 2283-2290.

26. Z. L. Xie, Y. Liu and H. Hanninen: 'Stabilization of retained austenite due to partial martensitic transformations', Acta Metall. Mater., 1994, 42, (12), 4117-4133.

27. Z. Nishiyama: 'Martensitic transformation'; 1978, New York, Academic Press.

28. G. B. Olson and M. Cohen: 'A perspective on martensitic nucleation', Annu. Rev. Mater. Sci., 1981, 11, 1-30.

29. A. Shibata, T. Murakami, S. Morito, T. Furuhara and T. Maki: 'The origin of midrib in lenticular martensite', Mater. Trans., 2006, 49, (6), 1242-1248.

30. H. K. D. H. Bhadeshia: 'An aspect of the nucleation of burst martensite', J. Mater. Sci., 1982, 2, (17), 383-386.

31. S. Chatterjee, H. S. Wang, J. R. Yang and H. K. D. H. Bhadeshia: 'Mechanical stabilization of austenite', Mater. Sci. Technol., 2006, 22, 641-644.

32. J. R. Strife, M. J. Carr and G. S. Ansell: 'The effect of austenite prestrain above the Md temperature on the martensitic transfor- mation in Fe-Ni-Cr-C alloys', Metall. Trans. A, 1977, $8 \mathrm{~A}, 1471-1483$.

33. R. Datta, G. Ghosh and V. Raghavan: 'Plastic accommodation during growth of the martensitic plates in Fe-Ni alloys', Scr. Metall., 1986, 20, 559-563. 
34. S. Kajawara: 'Roles of dislocations and grain boundaries in martensite nucleation', Metall. Trans. A, 1986, 17A, 1693-1702.

35. S. M. C. Van Bohemen and J. Sietsma: 'Kinetics of martensite formation in plain carbon steels: critical assessment of possible influence of austenite grain boundaries and autocatalysis', Mater. Sci. Technol., 2014, 30, (9), 1024-1033

36. S. M. C. van Bohemen and J. Sietsma: 'Martensite formation in partially and fully austenitic plain carbon steels', Metall. Mater. Trans. A, 2009, 40A, 1059-1068.

37. M. Villa: 'Isohermal martensite formation'; 2014, Kgs. Lyngby, Technical University of Denmark, .

38. D. C. Ludwigson and A. M. Hall: 'The physical metallurgy of precipitation-hardenable stainless steel', DMIC Report III, 1959, Battelle Mem. Inst., Columbus, OH.

39. C. J. Slunder, A. F. Hoenie and A. M. Hall: 'Thermal and mechanical treatment for precipitation-hardening stainless steel'; 1967, Washington, DC, NASA.

40. I. Sakamoto, N. Hayashi, B. Furubayashi and H. Tanque: 'Fe ion- induced phase transformation in 17/7 stainless steel', Hyperfine Interact., 1988, 42, 1005-1008.

41. E. Johnson, H. Johnasen and L. Sarholt-Kristensen: 'Ion implantation and martensitic transformation in 17/7 stainless steel', Nuclear Instrum. Methods Phys. Res., 1985, B7/8, 212 218.

42. J. A. Klostermann and W. G. Burgers: 'Surface martensite in iron- nickel', Acta Metall., 1964, 12, (4), 355-360.

43. J. F. Breedis: 'Martensitic transformations in iron-chromium- nickel alloys', Trans. AIME, 1964, 230, (7), 1583-1596.

44. L. D. Flansburg and N. Hershkowitz: 'Magnetism in austenitic stainless steel', J. Appl. Phys., 1970, 41, 4082

45. J. H. Lee, T. Fukuda and T. Kakeshita: 'Isothermal martensitic transformation in sensitized SUS304 austenitic stainless steel at cryogenic temperature', Mater. Trans., 2009, 50, (3), $473-$ 478.

46. L. Zhao, N. H. van Dijk, E. Bruck, J. Sietsma and S. van der Zwaag: 'Magnetic and X-ray diffraction measurements for the determination of retained austenite in TRIP steels', Mater. Sci. Eng. A, 2001, A313, (1-2), 145-152.

47. P. Merinov, S. Entin, B. Beketov and A. Runov: 'The magnetic testing of the ferrite content of austenitic stainless steel weld metal', NDT Int., 1978, 11, (1), 9-14.

48. B. D. Cullity and C. D. Graham: 'Introduction to magnetic materials', 2nd edn; 2009, New Jersey, Wiley-IEEE Press.

49. E. J. Mittemeijer: 'Analysis of the kinetics of phase transforma- tions', J. Mater. Sci., 1992, 27, (15), 3977-3987.

50. D. San Martin, N. H. van Dijk, E. Jime'nez-Melero, E. Kampert, U. Zeitler and S. van der Zwaag: 'Real-time martensitic transfor- mation kinetics in maraging steel under high magnetic fields', Mater. Sci. Eng. A, 2010, A527, 5241-5245.

51. A. Borgenstam and M. Hillert: 'Activation energy for isothermal martensite in ferrous alloys', Acta Mater., 1997, 45, (2), 651-662.

52. P. J. Withers and H. K. D. H. Bhadeshia: 'Overview - residual stress Part 2 - nature and origins', Mater. Sci. Technol., 2001, 17, 366-375.

53. B. Clausen, T. Lorentzen and T. Leffers: 'Self-consistent modelling of the plastic deformation of FCC polycrystals and its implications for diffraction measurements of internal stresses', Acta Mater., 1998, 46, (9), 3087-3098.

54. S. Morito, R. Igarashi, K. Kamiya, T. Ohba and T. Maki: 'Effect of cooling rate on morphology and crystallography of lath martensite in Fe-Ni alloys', Mater. Sci. Forum, 2010, 638-642, 1459-1463. 
55. G. B. Olson and M. Cohen: 'Dislocation theory of martensitic transformations', in 'Dislocations in solids', (ed. F. R. N. Nabarro), 7; 1986, Amsterdam, North Hollande Physics Pubblishing.

56. C. L. Magee: 'The kinetics of martensite formation in small particles', Metall. Trans., 1971, 2, (9), 2419-2430. 